\title{
Comparación de la cinética de la infección de ovas de trucha arcoíris (Oncorhynchus mykiss) con dos cepas de Piscirickettsia salmonis detectada mediante dot-blot"
}

\author{
J Larenas $^{1 *}$, C Gatica ${ }^{1}$, M Galleguillos ${ }^{2}$, H Adármes ${ }^{2}$, P Smith ${ }^{1}$ \\ ${ }^{1}$ Departamento de Patología Animal, Facultad de Ciencias Veterinarias y Pecuarias, Universidad de Chile \\ ${ }^{2}$ Departamento de Ciencias Biológicas, Facultad de Ciencias Veterinarias y Pecuarias, Universidad de Chile \\ Facultad de Ciencias Veterinarias y Pecuarias. Santa Rosa 11.735, La Pintana. Casilla 2, correo 15, \\ La Granja. Email: jlarenas@uchile.cl
}

\begin{abstract}
Resumen
En un estudio previo, se comprobó mediante microscopía de barrido, que la cepa LF-89 se adhiere a la pared de la ova mediante prolongaciones de su membrana externa, estructuras que han sido denominadas "Complejo de Adhesión Piscirickettsial" o CAP, lo que facilitaría la posterior penetración de la bacteria al interior de la ova. Sin embargo, existen otras cepas aisladas, como la SLGO-95, que es más virulenta y resistente a antibióticos que la LF-89 y que no se ha estudiado la posibilidad de unión a ovas. Por lo anterior, en el presente trabajo se comparó la cinética de infección de ovas de trucha arcoíris, entre ambas cepas, utilizando como metodología la técnica de dot-blot. El método de "dot-blot" se realizó mediante la retención de proteínas en una membrana de polivinildifluoruro (PVDF), incubación con anticuerpos oligoclonales anti-P. salmonis y posteriormente con un segundo anticuerpo anti inmunoglobulina $\mathrm{G}$ de ratón conjugado con peroxidasa. La reacción antígeno-anticuerpo se evidenció mediante un sustrato quimioluminiscente, utilizando una película autorradiográfica. La evaluación de la reacción se realizó mediante densitometría utilizando un "software" computacional. Para estandarizar el método se realizaron diluciones seriadas de la suspensión de P. salmonis, desde 0,02 a $56 \mu$ g de proteína total. Para aumentar la sensibilidad se centrifugaron las muestras a $11.000 \mathrm{x}$ g por $60 \mathrm{~min}$. Además, se probaron diferentes concentraciones de anticuerpo primario, 1:1000, 1:5000 y 1:10.000 y muestras de ovas y bacteria fueron sometidas a desnaturalización por ebullición. Se utilizaron ovas de reproductores libres de infecciones virales, Renibacterium salmoninarum y P. salmonis. Las ovas fueron incubadas (en duplicado) con $500 \mu \mathrm{L}$ de una suspensión de P. salmonis, ya sea con la cepa LF-89 o SLGO-95 por 1,3, 10 y 60 min. Luego, cada ova fue congelada a $-70^{\circ} \mathrm{C}$ hasta ser procesada para la técnica de "dot blot". La muestra no centrifugada de P. salmonis fue detectada como positiva sólo hasta $0,4 \mu \mathrm{g}$ de proteína total. Cuando fue centrifugada a $11.000 \mathrm{~g}$ por $1 \mathrm{~h}$, la bacteria fue detectada hasta la última dilución estudiada $(0,02 \mu \mathrm{g})$. Por otra parte, no hubo grandes diferencias en la positividad obtenida mediante las tres diluciones de anticuerpos primarios. De acuerdo, al "background" obtenido y nitidez, se consideró como una mejor dilución de trabajo 1:5000. Cuando se realizó la cinética de infección con la cepa LF-89, los resultados indicaron la aparición de señal positiva desde 1 min de exposición de las ovas a la bacteria. La reacción positiva se mantuvo hasta los $60 \mathrm{~min}$. Con respecto a la cepa SLGO-95, los resultados fueron similares, sin embargo, la cepa SLGO-95 demostró un mayor número de píxeles, lo que indica que esta cepa se une a la ova en mayor cantidad. Los resultados apoyan los estudios anteriores que indican que P. salmonis es capaz de infectar verticalmente las ovas y que esta podría ser una de las formas de transmisión del agente en condiciones de cultivo. Además, se comprueba que el grado de infección depende del tipo de cepa actuante.
\end{abstract}

Palabras clave: trucha arcoiris, Piscirickettsia salmonis, Transmision vertical. 


\section{Introducción}

La piscirickettsiosis es una enfermedad septicémica, que se presenta en países del hemisferio norte y en Chile, en centros de cultivos de salmónidos, especialmente, durante la fase de desarrollo en agua de mar. En nuestro país, ha provocado cuantiosas pérdidas económicas debido a las altas tasas de mortalidad y costo de tratamiento.

El agente etiológico de la enfermedad es una bacteria denominada Piscirickettsia salmonis, la cual fue aislada por primera vez en el sur de Chile en 1989 (Fryer y col 1990, Cvitanich y col 1991). La cepa de referencia se denomina LF-89, sin embargo, hasta la fecha han sido aisladas y caracterizadas otras variantes, entre ellas, la SLGO-95 (Smith y col 1996), que ha demostrado tener una alta virulencia y resistencia a algunos antimicrobianos.

Las vías de transmisión de la enfermedad aún no están claramente definidas. Se ha descrito, experimentalmente, que la bacteria puede penetrar por piel y branquias intactas (Smith y col 1999), aunque el mecanismo preciso de entrada por estas vías no es conocido. Con relación a la transmisión vertical, se ha demostrado que el agente se puede transmitir desde reproductores, machos y/o hembras experimentalmente infectados, hacia su progenie. Es así como el agente se ha detectado en ovas al "estado de ojo", alevines de saco y peces de 1 g (Larenas y col 2003). Recientemente, se ha descrito la transmisión vertical en salmones de cultivo. Los alevines infectados no presentaron signos o síntomas de la enfermedad, sin embargo, son capaces de excretar el agente por vía fecal (Larenas y col 2005).

En un estudio reciente, se comprobó mediante microscopía de barrido, que la cepa LF-89 se adhiere a la pared de la ova mediante prolongaciones de su membrana externa, estructuras que han sido denominadas "Complejo de Adhesión Piscirickettsial" o CAP, lo que facilitaría la posterior penetración de la bacteria al interior de la ova (Larenas y col 2003).

A pesar de que existen publicaciones que demuestran diferencias en virulencia y sensibilidad frente a quimioterápicos, no se conoce si la infección de la ova in vitro es similar para diferentes cepas bacterianas de $P$. salmonis. Por lo anterior, el presente trabajo consistió en establecer, mediante la técnica de "dot blot", la cinética de infección de la bacteria a ovas de trucha arcoíris (Oncorhynchus mykiss), comparando las cepas LF-89 y SLGO-95. Cabe destacar que es la primera vez que se utiliza esta metodología para detectar la infección con $P$. salmonis.

\section{Materiales y metodos:}

El presente trabajo experimental se realizó en las unidades de Anatomía Patológica y Patología de Organismos Acuáticos del Departamento de Patología Animal y, en el Laboratorio de Bioquímica y Química del Departamento de Ciencias Biológicas Animales de la Facultad de Ciencias Veterinarias y Pecuarias de la Universidad de Chile.

\subsection{Peces}

Se utilizaron 30 reproductores de trucha arcoíris $(O$. mykiss) de $800 \mathrm{~g}$ de peso, provenientes de una piscicultura de la Quinta Región, donde no se han reportado casos de piscirickettsiosis. Una vez llegados al laboratorio fueron sometidos a un periodo de cuarentena y tratados preventivamente contra hongos y parásitos externos. Los peces fueron mantenidos en la Unidad Experimental del Departamento de Patología Animal de la Facultad de Ciencias Veterinarias y Pecuarias de la Universidad de Chile en un estanque plástico de $2.500 \mathrm{~L}$ de capacidad, al cual se le suministró agua potable permanente filtrada $\mathrm{y}$ declorada por un filtro automático de carbón activado. El agua de salida fue clorada (5 ppm) y tratada mediante luz UV. El estanque tenía suministro de aire continuo mediante un sistema de bombas independientes. Los peces fueron alimentados dos veces al día con una dieta de mantención al $1 \%$ del peso vivo, mediante un alimento en "pellet" de origen comercial. Un grupo de 10 peces fue sometido a eutanasia para establecer el estado sanitario de los reproductores, realizándose necropsia y toma de muestras de frotis renal para evaluarlos mediante la técnica de inmunofluorescencia para la detección de Renibacterium salmoninarum y para Piscirickettsia salmonis, esto último mediante la técnica establecida por Lannan y col (1991), modificada por Larenas y col (1996). 


\subsection{Ovas}

Las ovas fueron obtenidas mediante frezado manual durante el periodo de desove (abril - mayo) y posteriormente depositadas en un recipiente estéril evaluándose su calidad, mediante inspección externa, no debiendo presentar señales de sobremaduración, de acuerdo a lo establecido por Blanco (1995).

\section{Piscirickettsia salmonis}

Se utilizaron las cepas LF-89 y SLGO-95, las cuales estaban preservadas en nitrógeno líquido. La bacteria fue multiplicada en la línea celular CHSE-214 en medio esencial mínimo de Eagle con sales de Earle (MEM), libre de antibióticos y suplementada con $10 \%$ de suero fetal bovino (MEM-10) incubada a $18^{\circ} \mathrm{C}$, de acuerdo a la metodología establecida por Fryer y col (1990). El microorganismo fue utilizado una vez que se observó un efecto citopático cercano al 100\%. El sobrenadante fue titulado mediante la dilución punto final en placa (Reed y Muench 1938) utilizándose un título de $10^{5,3} \mathrm{TCID}_{50} / \mathrm{mL}$. Previo al estudio de cinética la suspensión bacteriana fue filtrada pasándola por un filtro con poros de $5 \mu \mathrm{m}$.

\section{3. "Dot Plot"}

La concentración de proteínas totales se determinó mediante el método espectrofotométrico de Lowry usando como estándar albúmina sérica de bovino (Lowry y col 1951). Para realizar el procedimiento "dot blot" se utilizó un aparato BioDot - Bio-Dot $\AA$ Apparatus, BioRad - conectado qa una bomba de vacío. Las proteínas fueron retenidas en una membrana de polivinildifluoruro (PVDF) - Inmun-Blot ${ }^{\circledR}$ PVDF Membrane for Protein Blotting 0,2 $\mu \mathrm{m}$, BioRad. La metodología empleada consistió principalmente en la activación de la membrana PVDF con metanol por 20 s, lavado con agua destilada por 1 min y con "buffer" PBS por $2 \mathrm{~min}$, carga de las muestras, bloqueo con una solución de TBS 1X Tween 20 con leche descremada al $6 \%$ en refrigeración por $24 \mathrm{~h}$, incubación por $2 \mathrm{~h}$ con anticuerpo oligoclonal, el cual corresponde a una mezcla de seis anticuerpos monoclonales Inmunoglobulina $\mathrm{G}$ de ratón anti-P. salmonis, Kit SRS Fluorotest Indirecto, BiosChile. Luego se realizó la incubación con un segundo anticuerpo, anti Ig G de ratón elaborado en cabra y conjugado con peroxidasa ImmunoPure Antibody Horseradish Peroxidase, Pierce - por $1 \mathrm{~h}$ en dilución 1:15.000. Para evidenciar la reacción antígeno-anticuerpo se utilizó un sustrato quimioluminiscente - Super Signal, Chemiluminiscent Horseradish Peroxidase, Pierce. Las muestras fueron expuestas a una película autorradiográfica - CIXPosure $^{\mathrm{TM}}$ Film $5 \times 7$ in, Pierce - dentro de un "cassette" de exposición - Exposure cassette, vinylcovered with Velcro ${ }^{\circledR}$ closure For 8 x 10 in film, Sigma-Aldrich - por 10 a 30 min. Finalmente se realizó el revelado de la película y su evaluación mediante densitometría por un "software" computacional - UnScan-It Versión 4.1, 1996.

Para establecer la sensibilidad del método se realizaron ensayos con diluciones seriadas del cultivo bacteriano. Se procedió a diluir la muestra de cepa LF-89 con solución "buffer" PBS pH 7,4, obteniendo concentraciones de proteínas total de: $56,28,14,7$, 3,$5 ; 1,7 ; 0,8 ; 0,4 ; 0,28$ y $0,02 \mu \mathrm{g}$. Posteriormente se realizaron diluciones mayores $\left(10^{-1}, 10^{-2}\right.$ y $\left.10^{-3}\right)$ desde la muestra inicial que contenía $2,8 \mu \mathrm{g} / \mu \mathrm{L}$ de proteína, de esta manera en cada pocillo se cargaron $10 \mu \mathrm{L}$ de muestra sin diluir $(28 \mu \mathrm{g}$ proteína total $), 10 \mu \mathrm{L}$ de dilución $10^{-1}$ (2,8 $\mu \mathrm{g}$ proteína total), $10 \mu \mathrm{L}$ de dilución $10^{-2}(0,28 \mu \mathrm{g}$ proteína total $)$ y $10 \mu \mathrm{L}$ de dilución $10^{-3}$ $(0,028 \mu \mathrm{g}$ de proteína total). En ambos casos se incubó la membrana por $2 \mathrm{~h}$ con el primer anticuerpo diluido 1:5.000 y $1 \mathrm{~h}$ con el segundo anticuerpo diluido 1:15.000. Para mejorar la detección se procedió a centrifugar las muestras a $11.000 \mathrm{x}$ g por $60 \mathrm{~min}$ y luego se resuspendió el "pellet" en $150 \mu \mathrm{L}$ de PBS pH 7,4 .

Para establecer la mejor dilución del primer anticuerpo, se cargaron tres membranas con muestras de control positivo de $P$. salmonis, cada una correspondiente a una concentración del anticuerpo. En cada membrana se cargaron 5 y $10 \mu \mathrm{L}$ de muestra (14 y $28 \mu \mathrm{g}$ total de proteína) y la misma cantidad de la muestra bacteriana diluida $10^{-1} \quad(1,4 \quad$ y $2,8 \mu \mathrm{g}$ de proteína total). Posteriormente las membranas fueron incubadas en recipientes individuales con el primer anticuerpo en diluciones $\quad 1: 1.000, \quad 1: 5.000 \quad$ y $\quad 1: 10.000$ respectivamente. 
Con el objetivo de comprobar si existían diferencias entre las muestras en la condición nativa o desnaturalizada, una alícuota se calentó a baño maría durante $10 \mathrm{~min}$ (P. salmonis y ovas). Posteriormente, en los pocillos se cargaron $10 \mu \mathrm{L}$ de muestra de sobrenadante de cultivo celular infectado con $P$. salmonis sin hervir ( $28 \mu \mathrm{g}$ de proteína total), $10 \mu \mathrm{L}$ de homogeneizado de ova sin hervir $(20 \mu \mathrm{g}$ de proteína total), $10 \mu \mathrm{L}$ de $P$. salmonis hervida y $10 \mu \mathrm{L}$ de homogeneizado de ova hervida. La membrana se incubó con el primer anticuerpo diluido 1:5.000 por $2 \mathrm{~h}$ y el segundo anticuerpo diluido 1:15.000 por $1 \mathrm{~h}$.

\subsection{Cinética de la infección de ovas con $P$. salmonis Cepa LF-89}

Las ovas se dividieron en 6 grupos ( 2 ovas por cada grupo): 1, 3, 10 y $60 \mathrm{~min}$. Se colocaron en tubos Eppendorf de 1,5 mL, a los cuales se les agregó $500 \mu \mathrm{L}$ de sobrenadante de un cultivo celular con efecto citopático cercano al $100 \%$ que se encontraba en su pasaje número 29. Se utilizó un título de $10^{5,0}$ $\mathrm{TCID}_{50} / \mathrm{mL}$ para cada desafío. Transcurridos los tiempos de incubación se eliminó el cultivo bacteriano y se realizaron dos lavados con PBS $\mathrm{pH} 7,4$. Posteriormente las ovas fueron congeladas a $-70^{\circ} \mathrm{C}$ hasta su procesamiento. Se utilizaron además dos grupos controles negativos (5 y $60 \mathrm{~min}$ ), que correspondieron a ovas que se incubaron sin bacterias y con sólo $500 \mu \mathrm{L}$ de MEM.

Cada ova, individualmente, fue depositada en un tubo de centrifugación de $5 \mathrm{~mL}$. Se le agregó $1 \mathrm{~mL}$ de "buffer" de homogeneización, el cual consistió en una mezcla de "buffer" Tris pH 7,4 con inhibidores de proteasas. Fue procesado en un homogeneizador tres veces por $15 \mathrm{seg}$ en hielo. El homogeneizado resultante fue centrifugado a $1.000 \mathrm{x} \mathrm{g}$ durante $20 \mathrm{~min}$ para eliminar los restos celulares groseros. Se recuperó el sobrenadante y se centrifugó a 11.000 x g durante 60 min. Finalmente, se eliminó el sobrenadante y el "pellet" fue nuevamente suspendido en $150 \mu \mathrm{L}$ de PBS. Esta suspensión final fue posteriormente analizada mediante "dot blot". Como control de viabilidad de la bacteria, una parte del sobrenadante, utilizado para infectar las ovas, fue inoculado y titulado en la línea CHSE-214.

\section{Cepa SLGO-95}

Las ovas se dividieron en 6 grupos ( 2 ovas por cada grupo): 1, 3, 10 y $60 \mathrm{~min}$. Se colocaron en tubos Eppendorf de 1,5 mL, a los cuales se les agregó $500 \mu \mathrm{L}$ de sobrenadante de un cultivo celular con efecto citopático cercano al $100 \%$ que se encontraba en su pasaje número 10. Al igual que para la cepa LF-89, se utilizó un título de $10^{5,0} \mathrm{TCID}_{50} / \mathrm{mL}$ para cada desafío. Transcurridos los tiempos de incubación se eliminó el cultivo bacteriano y se realizaron dos lavados con PBS $\mathrm{pH} 7,4$. Posteriormente las ovas fueron congeladas a $70^{\circ} \mathrm{C}$ hasta su procesamiento. Cada ova, individualmente, fue procesada de la misma forma que se explicó anteriormente para la cepa LF-89.

\subsection{Análisis de resultados}

En cada membrana se cargó una muestra de sobrenadante de cultivo celular de P. salmonis, cuyos píxeles totales, medidos por densitometría, correspondieron como referencia al $100 \%$ de carga bacteriana inicial. Posteriormente, el número de píxeles del resto de las muestras se expresó como porcentaje de infección de la ova con respecto a la dosis inicial. Se realizó un análisis descriptivo con relación al tiempo y porcentaje de infección de la ova. Para comparar los resultados entre las dos cepas se realizó un análisis estadístico por medio de la prueba de t-student para dos variables.

\section{Resultados}

La Los peces fueron sometidos a eutanasia $y$ analizados para el control de salud no evidenciaron lesiones anátomo-patológicas a la necropsia. Las pruebas de inmunofluorescencia entregaron resultados negativos a la presencia de Renibacterium salmoninarum y Piscirickettsia salmonis.

Con respecto a la sensibilidad del método los resultados indicaron una disminución progresiva de la reacción a medida que se diluía la cepa hasta la última dilución estudiada (Figura 1). La reacción no se detectó a partir de los $0,28 \mu \mathrm{g}$ de proteína total. Estos resultados correspondieron a la cepa no centrifugada. Cuando la suspensión bacteriana se centrifugó a 11.000 x g por 60 min las muestras resultaron positivas aún en 
la última dilución estudiada $(0,02 \mu \mathrm{g}$ de proteína total $)$ (Figura 2). En relación con la dilución del primer anticuerpo, la cepa LF-89 fue detectada en todas las diluciones empleadas hasta la concentración de 1,4 $\mu \mathrm{g}$ de proteína total (Figura 3).

Cuando se realizó la cinética de infección con la cepa LF-89, los resultados indicaron la aparición de señal positiva desde $1 \mathrm{~min}$ de exposición de las ovas a la bacteria. La reacción positiva se mantuvo hasta los 60 min. Con respecto a la cepa SLGO-95, los resultados fueron similares, sin embargo, la cepa SLGO-95 demostró un mayor número de píxeles, lo que indica que esta cepa se une a la ova en mayor cantidad (Tabla 1, Figura 4).

La prueba estadística de t-student para dos variables entrega como resultado un valor en la zona de rechazo, lo que significa que existen diferencias significativas entre las cinéticas de la infección de las ovas de trucha arcoíris con los diferentes aislados de Piscirickettsia salmonis.

\begin{tabular}{|l|l|l|l|l|l|l|l|}
\hline Proteína Total $(\mu \mathrm{g})$ & $\mathbf{1 4}$ & $\mathbf{7}$ & $\mathbf{3 , 5}$ & $\mathbf{1 , 7}$ & $\mathbf{0 , 8}$ & $\mathbf{0 , 4}$ \\
\hline $\mathbf{5 6}$ & $\mathbf{2 8}$ & $\mathbf{1 4}$ & & & & & \\
\hline
\end{tabular}

Figura 1. "Dot blot". Diluciones de LF-89 con PBS, comenzando desde $56 \mu$ g de proteína se aprecia la disminución de la reacción de los anticuerpos hasta los $0,4 \mu \mathrm{g}$ de proteína.

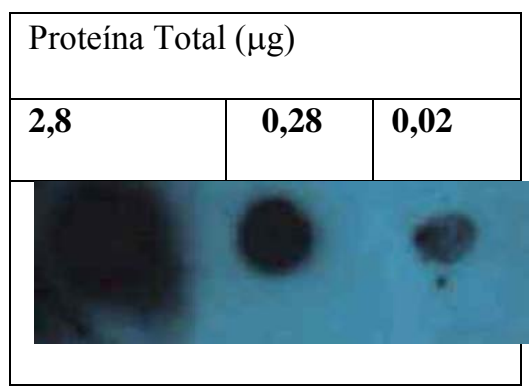

Figura 2. "Dot blot". Diluciones de LF-89 con PBS, centrifugadas a 11.000 x g por 60 min. Se aprecia la reacción positiva desde $2,8 \mu \mathrm{g}$ proteína total hasta la última dilución estudiada ( $0,02 \mu \mathrm{g}$ proteína total). 


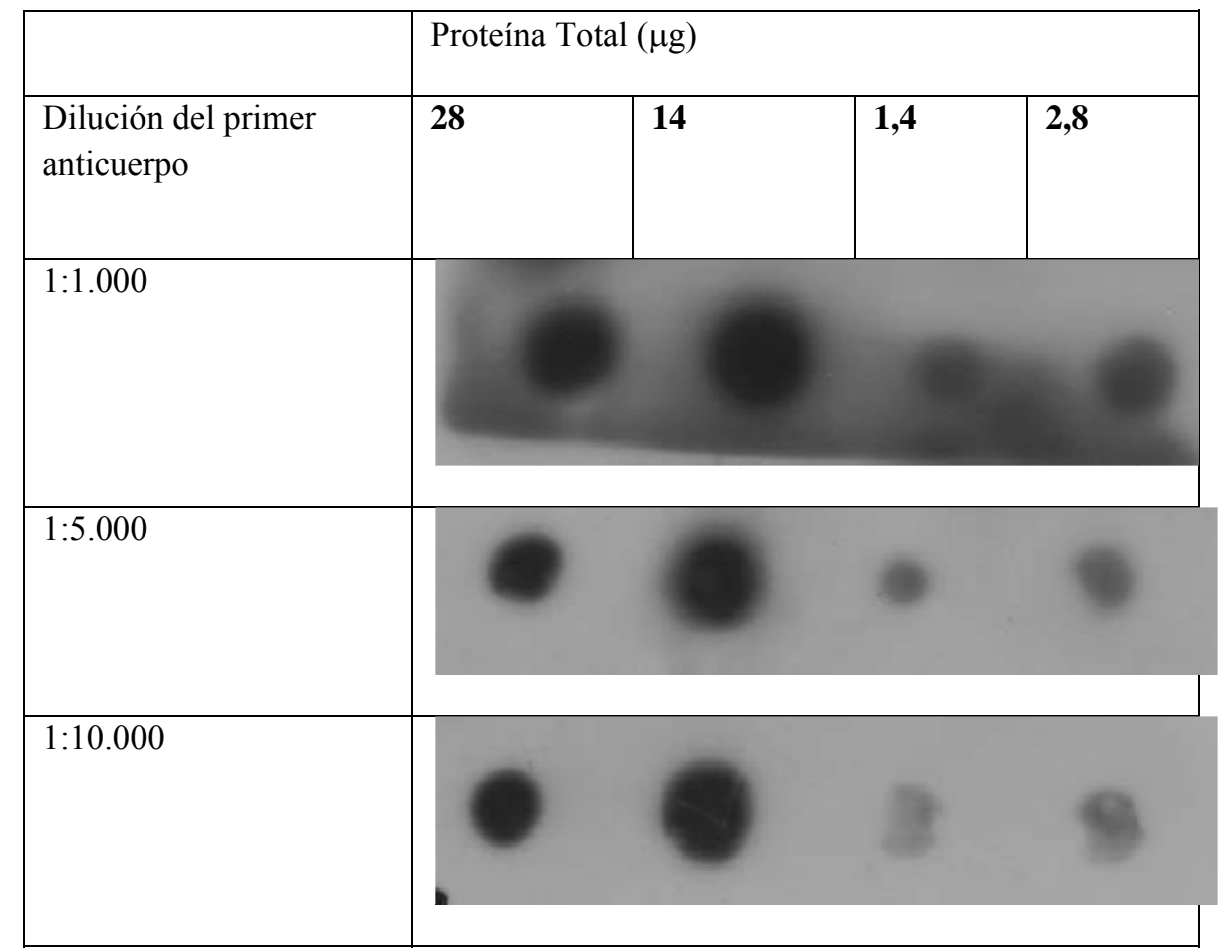

Figura 3. "Dot blot". Reacción contra la cepa LF-89 de Piscirickettsia salmonis a distintas diluciones del primer anticuerpo. En la primera fila se aprecia la membrana incubada con el primer anticuerpo diluido 1:1.000, en la segunda 1:5.000 y en la tercera fila 1:10.000. La reacción positiva se aprecia desde los $28 \mu \mathrm{g}$ de proteína total (primera columna) hasta los $1,4 \mu \mathrm{g}$ de proteína total (tercera columna).

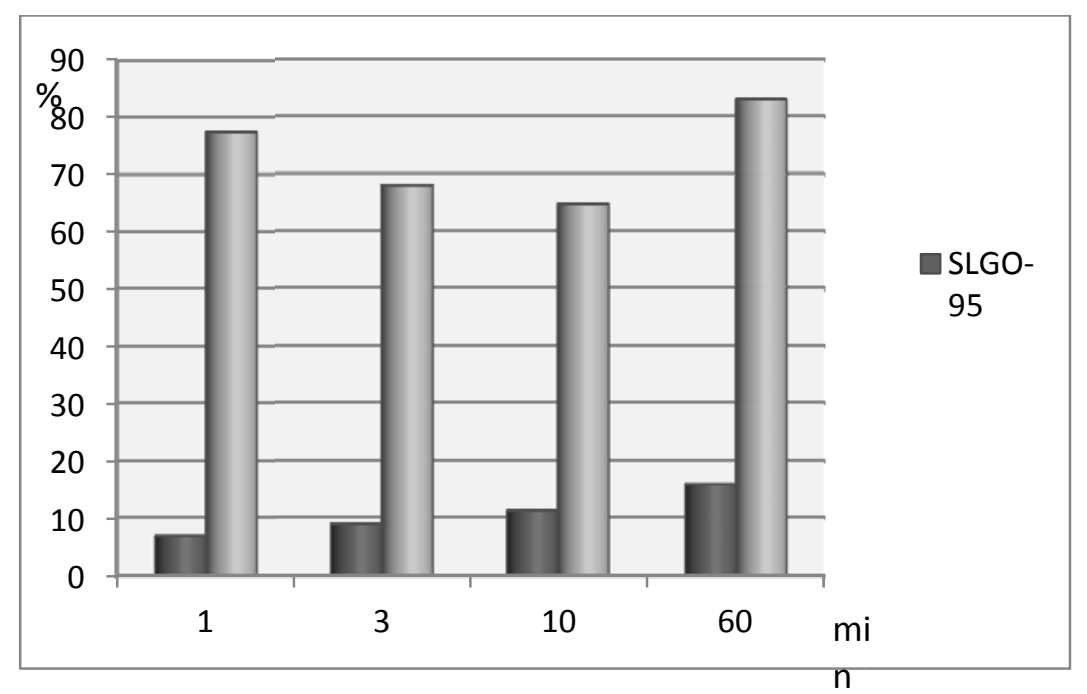

Figura 4. Cinética de infección de la cepas LF-89 y SLGO-95 en ovas de trucha arcoíris (O. mykiss), de acuerdo al tiempo de exposición. Los píxeles obtenidos por densitometría se expresan en porcentaje en relación al valor de carga inicial de exposición de las ovas. 
Tabla 1. Comparación entre los porcentajes de infección de ovas de trucha arcoíris (Oncorhynchus mykiss) con las cepas LF-89 y SLGO-95 de Piscirickettsia salmonis a diferentes tiempos de exposición. *El valor porcentual corresponde a la relación entre el número de píxeles obtenido por tiempo de exposición y el valor de carga inicial con la bacteria.

\begin{tabular}{ccc}
\hline $\begin{array}{c}\text { Tiempo de exposición } \\
\text { (min) }\end{array}$ & LF-89 (\%) & $\begin{array}{c}\text { SLGO-95 } \\
(\%)\end{array}$ \\
\hline 1 & $6,77^{*}$ & $77,38^{*}$ \\
3 & 8,95 & 67,93 \\
10 & 11,20 & 64,61 \\
60 & 15,76 & 82,81 \\
\hline
\end{tabular}

\section{Discusión}

El presente trabajo corresponde al primero donde se ocupa el método "dot blot" asociado a quimioluminiscencia para detectar Piscirickettsia salmonis. Por lo tanto, en una etapa inicial fue necesario estandarizar la técnica. Para el ensayo "dot blot" se ocupó el mismo primer anticuerpo que es utilizado en otras pruebas diagnósticas para $P$. salmonis como inmunofluorescencia $\mathrm{e}$ inmunoperoxidasa, que es de origen comercial. De acuerdo a la información disponible, este anticuerpo oligoclonal es específico contra distintas cepas de $P$. salmonis aisladas desde el sur del país. En el presente trabajo no se presentó reacciones cruzadas contra otros componentes como las células CHSE-214 ni las ovas, desnaturalizadas o no por la acción del calor, lo cual en parte es concordante con otros estudios (Jamett y col 2001).

En los estudios de especificidad del método se encontró reacción de los anticuerpos secundarios con el cultivo celular CHSE-214 sin lavar. Debido a que $P$. salmonis se desarrolla en la monocapa celular con MEM-10, fue necesario evaluar cada componente por separado para ver cual era el causante de la reacción positiva. Los resultados demostraron que la reacción se producía contra el cultivo celular con MEM-10 y contra el MEM-10, pero no contra el cultivo celular lavado con PBS. Por lo anterior aparece recomendable lavar adecuadamente la muestra de células antes de utilizarlas como control negativo, así como también lavar la muestra bacteriana. Ello aparentemente estaría demostrando que los anticuerpos secundarios reaccionan con el suero fetal bovino.

Para ver si existían factores físicos que hicieran desaparecer los epitopos o aparecer nuevos epitopos, se sometieron las muestras a ebullición. Sin embargo, los resultados indicaron que no existían diferencias luego de este proceso. El efecto de la desnaturalización no afectó la detección de la bacteria mediante la técnica.

Los experimentos de dilución del primer anticuerpo indicaron que había buena señal con el anticuerpo diluido 1:1.000, sin demasiado "background", sin embargo, se utilizaba mucho anticuerpo. También se obtuvieron buenos resultados con el anticuerpo diluido 1:10.000. Sin embargo, se seleccionó una dilución intermedia (1:5.000) para asegurar una buena señal positiva.

En el presente estudio se estableció la infección de las ovas de trucha arcoíris con las cepas LF-89 y SLGO-95 de $P$. salmonis mediante la técnica de "dot blot" asociada a quimioluminiscencia. Los resultados de la cinética son concordantes con estudios anteriores donde se señala que mediante microscopía electrónica de barrido se aprecia la cepa LF-89 adherida a la superficie de la ova desde los 20 segundos de exposición a la bacteria (Larenas y col 2003). En ese mismo estudio, se observó la bacteria ingresando a la 
ova atravesando el corión desde el primer minuto de exposición, siendo más evidente a los 30 y $60 \mathrm{~min}$. Además, se observó la presencia de la bacteria en el interior de la ova a los $5 \mathrm{~min}$ de exposición.

En un estudio experimental realizado por Larenas y col (2003) demostraron la presencia de $P$. salmonis en alevines que provenían de la fertilización de gametos de reproductores negativos a la infección con el agente. La fertilización se realizó en presencia de una suspensión que contenía la bacteria, por lo que se sugiere que ésta puede ingresar a los gametos durante este proceso.

Lannan y Fryer (1994) demostraron que la bacteria sobrevive pocos segundos en agua dulce, por lo que debe tener una estrategia que le permita ingresar rápidamente a la ova. El presente estudio apoyaría esta idea, de acuerdo a la aparición de infección desde el primer tiempo estudiado (1 min) para ambas cepas.

Cabe destacar que durante la ejecución de este trabajo se efectuó un experimento donde se incubó durante 10 min una ova con una suspensión bacteriana hervida a $100^{\circ} \mathrm{C}$ durante $10 \mathrm{~min}$, el cual no entregó resultado positivo a la incubación con los anticuerpos, lo cual señala que no hubo adhesión de la bacteria muerta a la ova y que la adhesión e ingreso de $P$. salmonis no es un proceso pasivo.

La cepa SLGO-95 demostró adherirse en mayor cantidad a la ova. Esto puede tener relación con estudios anteriores que señalan que este aislado es más virulento, ya que produce mortalidades más altas y en menor tiempo con relación a la cepa LF-89 (Smith y col 1997). Además, esta cepa es más resistente a las terapias antibacterianas (Smith y col 1996). Todo lo cual hacía suponer que SLGO-95 debería tener un comportamiento eficiente en cuanto a la adhesión e ingreso a diferentes tejidos, incluido la ova.

Cabe destacar que el presente estudio se hizo en paralelo a una Memoria de Título (Quinteros 2005) donde se realizó un estudio cinético, pero la unión de la bacteria a la ova se observó mediante microscopía de barrido, corroborando los resultados obtenidos, ya que se observó una mayor adhesión de la cepa SLGO-95 a la superficie de la ova.

Los resultados apoyan los estudios anteriores que indican que Piscirickettsia salmonis es capaz de infectar verticalmente las ovas y que esta podría ser una de las formas de transmisión del agente en condiciones de cultivo. Además, se comprueba que el grado de infección depende del tipo de cepa actuante.

\section{Referencia}

1. Blanco Mc. 1995. La Trucha: Cría Industrial. En "Reproducción De La Trucha Arcoíris", Ediciones Mundi-Prensa, Madrid, España, Pp. 110-130.

2. Cvitanich Jd, Gárate On, Smith Ce. 1991. The Isolation Of Rickettsia-Like Organism Causing Disease And Mortality In Chilean Salmonids And Its Confirmation By Koch's Postulate. J Fish Dis $14,121-145$.

3. Fryer Jl, Lannan Cn, Garcés Hl, Larenas Jj, Smith Pa. 1990. Isolation Of A Rickettsial-Like Organism From Diseased Coho Salmon (Oncorhynchus Kisutch) In Chile. Fish Pathol 25, 107-114.

4. Jamett A, Aguayo J, Miquel A, Muller I, Arriagada R, Becker Mi, Valenzuela P, Burzio Lo. 2001. Characteristics Of Monoclonal Antibodies Against Piscirickettsia Salmonis. J Fish Dis 24, 205-215.

5. Lannan Cn, Ewing Sa, Fryer Jl. 1991. A Fluorescent Antibody Test For Detection Of The Rickettsia Causing Disease In Chilean Salmonids. J Aquat Anim Health 3, 229-234.

6. Lannan Cn Y Fryer Jl.1994. Extracellular Survival Of Piscirickettsia Salmonis. J Fish Dis 17, 545548.

7. Larenas J, Astorga C, Contreras J, Garcés H, Fryer Jl, Smith P. 1996. Rapid Detection Of Piscirickettsia Salmonis Using Microwave Irradiation. Fish Pathol 31, 231-232.

8. Larenas $\mathrm{Jj}$, Bartholomew $\mathrm{J}$, Troncoso $\mathrm{O}$, Fernández S, Ledezma H, Sandoval N, Vera P, Contreras J, Smith P. 2003. Experimental Vertical Transmission Of Piscirickettsia Salmonis And In Vitro Study Of Attachment And Mode Of Entrance Into The Fish Ovum. Dis Aquat Org 56, 25-30.

9. Larenas J, Zamorano E, Smith P. 2005. Detección De Piscirickettsia Salmonis En Heces De Salmón Coho (Oncorhynchus Kisutch) Infectados Por Transmisión Vertical. Mon Electr Patol Vet 2, 5967.

10. Lowry Oh, Rosenbrough $\mathrm{Nj}$, Farr Al, Randal Rj. 1951. Protein Measurement With The Folin Phenol Reagent. J. Biol. Chem 193: 265-275.

11. Quinteros J. 2005. Comparación En La Presentación Del Complejo De Adhesión Piscirickettsial Entre Dos Cepas De Piscirickettsia 
Salmonis. Memoria Título Médico Veterinario. Facultad De Ciencias Veterinarias Y Pecuarias, Universidad De Chile. Santiago, Chile.

12. Reed Lj Y Muench H. 1938. A Simple Method Of Estimating Fifty Percent Endpoints. Am J Hyg 27, 497-499.

13. Smith Pa, Vecchiola Im, Oyanedel S, Garcés Lh, Larenas J, Contreras J. 1996. Antimicrobial Sensitivity Of Four Isolates Of Piscirickettsia Salmonis. Bull Eur Assoc Fish Pathol 16, 164 168.

14. Smith $\mathrm{Pa}$, Rojas Me, Larenas J, Contreras J, Guajardo A. 1997. Virulence Comparison Of Three Chilean Isolates Of Piscirickettsia Salmonis. En: Viiith International Conference. Diseases Of Fish And Shellfish. Abstracts Book. Heriot-Watt University, Edinburgh, Eur Assoc Fish Pathol Pp. P-056.

15. Smith Pa, Pizarro $\mathrm{P}$, Ojeda $\mathrm{P}$, Contreras J, Oyanedel S, Larenas J.1999. Routes Of Entry Of Piscirickettsia Salmonis In Rainbow Trout (Oncorhynchus Mykiss). Dis Aquat Org 37, 165172 